\title{
OS FAZERES DA HISTÓRIA: DE EUSÉBIO DE CESAREIA A GOMES EANES DE ZURARA
}

\section{Fernando Pereira dos Santos*}

Universidade Estadual Paulista Júlio de Mesquita Filho

Franca - São Paulo - Brasil

Resenha do livro: TEIXEIRA, I. S. E BASSI, Rafael (org.). A escrita da história na Idade Média. São Leopoldo: Oikos, 2015, 183 p.

Desde que a história tornou-se uma disciplina acadêmica em meados do século XIX, ${ }^{1}$ o seu fazer tem sido alvo de constantes inquirições por aqueles que se dedicam a esse ofício. Uma das questões perscrutadas é aquela que discute a existência ou não de "historiadores" durante os períodos anteriores a supracitada institucionalização e, mais especificamente, no decorrer dos

\footnotetext{
* Mestre e Doutorando em História pelo Programa de Pós Graduação em História da Faculdade de Ciências Humanas e Sociais e bolsista da Comissão de Aperfeiçoamento de Pessoal do Nível Superior - Capes. E-mail: fernando_trad@yahoo.com.br.

1 SOUTHERN, Richard. History and historians: selected papers by Richard Southern. Editado por Richard Bartlett. Malden, MA: Blackwell, 2004, p. 88-107.
} 
séculos balizados como Idade Média. ${ }^{2}$ Não há dúvidas de que Otto de Freising ou Jean Bossuet, por exemplo, tenham realizado empreitadas que hoje são classificadas como "históricas" e, a seu modo, todos aqueles empenhados em atividades congêneres produziram narrativas em que evidenciaram-se elementos imbuídos de sentido e verossimilhança atribuídos às configurações das formas de pensar existentes no momento de sua composição. Logo, é justamente da análise de parâmetros constituintes de verdades e, paralelamente, dos elementos que compõem alguns dos "gêneros" discursivos entendidos como históricos durante o medievo que trata a obra $A$ escrita da história na Idade Média, publicada pela Editora Oikos sob organização de Igor Salomão Teixeira e Rafael Bassi.

Dividida em oito capítulos escritos por diferentes autores, dentre os quais figuram grandes nomes da pesquisa em âmbito nacional, como Néri de Barros Almeida e Susani Silveira Lemos França, o livro conta também com a colaboração de José Miguel de Toro Vial, da Universidad Católica de la Santísisma Concepción, Chile. Em termos gerais, a obra apresenta ensaios que investigam alguns dos principais lugares comuns da composição histórica no medievo, como o recorrente eixo narrativo sobre guerra e governança, bem como o exercício das funções moralistas e memorialistas daqueles escritos para as sociedades em que foram concebidos. Esse é justamente um dentre seus vários destaques positivos, uma vez que permite ao leitor atentar-se para a existência daqueles parâmetros em escritos apartados entre si tanto no sentido do espaço geográfico temporal em que foram compostos como pelos homens que os conceberam, isto é, Eusébio de Cesareia (c. 264 - 339), Iacopo de Varagine (1228 - 1298), Jean Froissart (1337 - 1405), Gomes Eanes de Zurara (1410 - 1474), dentre tantos, e o afamado Jean Froissart. A esse fato somam-se outros de igual relevância: a observância que se faz acerca dos usos da retórica e da forte influência dos escritos clássicos e sagrados ao longo de todo o período, bem como as questões relevantes sobre a audiência

\footnotetext{
2 GALBRAITH, Vivian Hunter. Historical research in medieval England. Londres: University of London, 1951. GIVEN-WILSON, Christopher. Chronicles: the writing of history in late medieval England. Londres: Hambledon and London, 2004. GRANSDEN, Antonia. Historical writing in England. Londres: Routledge, 1996. GUENÉE, Bernard. História. In: LE GOFF, Jacques \& SCHMITT, Jean Claude (coord.). Dicionário temático do Ocidente medieval. Tradução de Hilário Franco Júnior. Bauru: Edusc; São Paulo: Imprensa Oficial do Estado, 2002. HAY, Dennis. Annalists and historians: western historiography from eighth to eighteenth centuries. Londres: Methuen; Nova York: Harper \& Row, 1977. SMALLEY, Beryl. Historians in the Middle Ages. Londres: Thames \& Hudson, 1974. TAYLOR, John. English historical literature in the fourteenth century. Oxford: Clarendon Press, 1987.
} 
pretendida por aqueles homens (e mulher), no caso, Anna Comenna, uma das únicas mulheres a produzir relatos históricos de que se tem notícia. ${ }^{3}$

A relação existente entre todo esse conteúdo é de suma importância para a compreensão dos problemas que cercaram a produção da história no medievo, como o número reduzido de leitores, o parco acesso a outros textos, a "censura" que poderiam vir a sofrer em diversos âmbitos, ${ }^{4}$ e mesmo o próprio processo de produção, cópia e manutenção dos escritos que poderiam trazer sérias implicações ao seu conteúdo. ${ }^{5}$ Ao relevarmos esses temas segundo seu horizonte de produção, é possível buscar seus possíveis significados para o exercício de reconstituição do passado caro a atividade do historiador.

Em nosso entendimento, A escrita da história na Idade Média em grande medida atende às expectativas dos estudiosos que, em algum momento de suas pesquisas, se depararam com essa rica e ampla temática. Em vários momentos da obra, levantam-se pontos de extrema relevância à inquirição acerca do fazer histórico medieval: por que em seus primórdios os cristãos não se interessavam pelo modelo clássico de se escrever história? ${ }^{6}$ Se tais modelos foram posteriormente mesclados e adaptados pelos mesmos cristãos, ${ }^{7}$ que forneceram os pilares para o registro histórico por ao menos um milênio no Ocidente, ora ativeram-se a tais paradigmas ${ }^{8}$ ora extrapolaram o que se esperava deles (p. 157), mas nem por isso deixaram de partilhar premissas em comum na configuração de saberes sobre outrora para a realização de suas narrativas. ${ }^{9}$

Além dessas, pontuamos algumas dentre as diversas questões lançadas pelos autores que, a nosso ver, igualmente dialogam entre si: o que se pode

\footnotetext{
3 De forma geral, os cronistas integravam um universo composto por homens de meia idade, majoritariamente clérigos e pertencentes às elites terratenentes (GIVEN-WILSON, Christopher, op. cit., p. 60-64).

${ }^{4}$ GIVEN-WILSON, Christopher, op. cit., p. 207-212.

${ }^{5}$ The manuscript experience: what medieval vernacular manuscripts tell us about authors and texts. In: CAIE, Graham \& REVENEY, Denis (ed.). Medieval texts in context. Londres: Routledge, 2008, p. 10-27.

6 ALMEIDA, Neri de Barros \& DELLA TORRE, Robson Murilo Grando. A História eclesiástica de Eusébio de Cesareia frente à tradição historiográfica clássica. In: TEIXEIRA, Igor Salomão \& BASSI, Rafael, obra desta resenha, p. 15.

7 FRANÇA, Susani Silveira Lemos. A rememoração do passado no rastro da prudência. In: TEIXEIRA, Igor Salomão \& BASSI, Rafael (org.), obra desta resenha, p. 66-68.

${ }^{8}$ MIATELLO, André Luis Pereira. Iacopo de Varagine a escrita da história no século XIII. In: TEIXEIRA, Igor Salomão \& BASSI, Rafael (org.), obra desta resenha, p. 119-124.

9 BASSI, Rafael. Anna Commena, historiadora. Um estudo sobre a escrita da história no Império bizantino: o caso d'A Alexíada (séculos XI - XII). In: TEIXEIRA, Igor Salomão \& BASSI, Rafael (org.), obra desta resenha, p. 44-45.
} 
rev. hist. (São Paulo), n. 174, p. 433-440, jan.-jun., 2016 http://dx.doi.org/10.11606/issn.2316-9141.rh.2016.112288
Fernando Pereira dos Santos

Os fazeres da História: de Eusébio de Cesareia a Gomes Eanes de Zurara

inferir das possíveis intencionalidades dos responsáveis por aquela escrita da história a partir da leitura de seus prólogos, ${ }^{10}$ uma vez que ali muitas vezes o responsável pela composição textual enuncia seus interesses para o desempenho da escrita. Não obstante, quem seria seu possível público em uma era em que a capacidade técnica da escrita e a habilidade para a leitura restringiu-se a uma fração das sociedades em pauta? ${ }^{11}$ Talvez a grande questão que permeia todas as outras seja, enfim, refletir sobre os porquês e a utilidade em se registrar a história em suporte escrito. ${ }^{12}$ Muito embora tais questionamentos tenham sido realizados ao longo da obra a partir de documentos específicos tendo em vista momentos esporádicos, o que pudemos notar através de sua leitura é a presença de tópicos em comum partilhados por homens muitas vezes sem contato entre si, mas, de alguma forma, continuadores e transformadores de formas prévias de organização do conhecimento.

Contudo, no nosso entendimento, a obra não explora todo o seu potencial, e deixa escapar boas oportunidades de discussão - quiçá para uma futura continuação - acerca de outras matérias que circundam a problemática da escrita da história na Idade Média. Notamos que os ensaios, de modo geral, ainda se concentram em grande medida no medievo latino - Portugal, Espanha, França, Itália - da baixa Idade Média (séculos XIV-XV), reflexo talvez da incidência sobre tal eixo nos cursos de história no Brasil, onde ainda são poucas, mas não menos significativas, as pesquisas sobre outros lugares, tempos e "povos", como os britânicos, escandinavos e germânicos, e mesmo sobre o mundo não cristão ou mesmo apartado dos ditames da Igreja: árabes, asiáticos e reinos africanos. ${ }^{13}$ Uma breve, porém valiosa, inquirição nesse sentido foi feita por Marcella Guimarães, que analisou a introdução dos Prolegômenos do tunisiano Ibn Khaldun (1332-1406) em face aos escritos de Jean Froissart (1337-1405), Pero Lopez de Ayala (1332-1407) e Fernão Lopes (1390-1460). Porém o que mais podem nos dizer outras vozes coevas não confinadas ao claustro monástico ou mesmo às atividades burocráticas no

\footnotetext{
${ }^{10}$ GUIMARÃES, Marcella Lopes. As intenções da escrita da História no outono da Idade Média. In: TEIXEIRA, Igor Salomão \& BASSI, Rafael (org.), obra desta resenha, p. 76-77.

${ }^{11}$ SIQUEIRA, André Luiz. Fantasmas celanenses: os usos do "Memoriale beati Francisci in desiderio aimae" na formação de uma consciência histórica franciscana no século XIII. In: TEIXEIRA, Igor Salomão \& BASSI, Rafael (org.), obra desta resenha, p. 93.

${ }^{12}$ MIATELLO, André Luis Pereira. Iacopo de Varagine a escrita da história no século XIII. In: TEIXEIRA, Igor Salomão \& BASSI, Rafael (org.), obra desta resenha, p. 114.

${ }^{15}$ MACEDO, José Rivair. Os estudos medievais no Brasil: uma tentativa de síntese. Reti Medievali Rivista, Firenze, vol. 7, n. 1, 2006, p. 1-9. Disponível em: http://www.dssg.unifi.it/_RM/rivista/ saggi/RivairMacedo.htm. Acesso em: 03/03/2016.
} 
Mediterrâneo? Nesse sentido, o capítulo que finaliza o livro, de José Miguel de Toro Vial, oferece uma perspectiva interessante ao analisar o panorama da construção de uma cosmovisão partilhada por crônicas "universais", ${ }^{14}$ uma das possíveis formas de se conceber a escrita da história iniciada na Antiguidade tardia e que perdurou para muito além do período abarcado na obra, embora igualmente sua análise se concentre nos textos da Europa cristã. ${ }^{15}$

Outro ponto praticamente ignorado foi o da contribuição de laicos nesse contexto a partir do século XIV. André Luis Pereira Miatello lança bons questionamentos sobre a escrita do bispo Iacopo de Varegine e a relação com a não inserção de Gênova, ao contrário das outras cidades italianas, no movimento humanista, em que afirma que os litterati leigos escassearam e os dominicanos assumiram a produção cultural local. ${ }^{16}$ Entretanto, em uma obra que trata em sua maioria de ensaios feitos a partir de textos concebidos com funções primordialmente religiosas, uma inversão de perspectiva poderia oferecer novos ângulos de observação ao leitor, isto é, lançando olhares para o crescente número de laicos que despontou para fins diversos na escrita da história, e para os elementos e interesses presentes em sua forma de registar o passado, como a difusão de textos para além de círculos nobiliárquicos, para finalidades que extrapolavam o entretenimento e a moralização e nem sempre escritos apenas em latim, mas também em idiomas vernáculos. ${ }^{17}$ Assim, até que ponto eles teriam continuado a escrita da história amparada por elementos cristãos? Seria possível notar novos elementos na abordagem, na escrita, ou mesmo na escolha do que figurar em seus escritos, que destoavam de uma escrita marcadamente escatológica? ${ }^{18}$

Uma última questão, a nosso ver, que permeia as discussões sobre a escrita da história na Idade Média e que foi pouco discutida refere-se aos supracitados "gêneros" discursivos. No prólogo, seus responsáveis afirmam ser importante questionarmos se houve a escrita da história, quem escrevia, com quais intuitos e, também, destacamos aqui de que forma era feita ${ }^{19}$.

\footnotetext{
${ }^{14}$ VIAL, José Miguel de Toro. As crônicas universais e a cosmografia medieval. In: TEIXEIRA, Igor Salomão \& BASSI, Rafael (org.), obra desta resenha, p. 177-179.

${ }^{15}$ Idem, p. 159.

${ }^{16}$ MIATELLO, André Luis Pereira. Iacopo de Varagine a escrita da história no século XIII. In: TEIXEIRA, Igor Salomão \& BASSI, Rafael (org.), obra desta resenha, p. 116.

${ }^{17}$ RICHARDSON, Malcolm. Middle-class writing in late medieval London. Londres: Pickering \& Chatto, 2011.

${ }^{18}$ VIAL, José Miguel de Toro. As crônicas universais e a cosmografia medieval. In: TEIXEIRA, Igor Salomão \& BASSI, Rafael (org.), obra desta resenha, p. 162-164.

${ }^{19}$ TEIXEIRA, Igor Salomão. Ystoria sancti Thome de Aquino: hagiografia ou história? In: TEIXEIRA, Igor Salomão \& BASSI, Rafael (org.), obra desta resenha, p. 7.
} 
Inúmeras são as elucubrações sobre a relação existente entre formas de escrita, como crônicas, anais e hagiografias e o relato histórico, ${ }^{20}$ pois como se pergunta Igor Salomão Teixeira em seu ensaio, "o que se entendia por história na Idade Média? Mais especificamente, qual o estatuto de um texto entitulado (sic) por história escrito no início do século XIV?"21 Sucintamente, uma vez que a pretensão à veracidade está ligada não apenas ao que se narra, mas ao como se narra, ${ }^{22}$ é importante que se traga à tona de que maneira se relaciona a forma organizacional do texto, em sentido mais amplo, com as funções da história na Idade Média. A escrita em qualquer uma das formas assumidas não ocorreu de modo linear, mas simultaneamente: o que isso nos diz sobre o entendimento daqueles indivíduos sobre o objeto que produziram, refletiram e empregaram para fins diversos?

De qualquer forma, para além de registros em que, muitas vezes, imperou o maravilhoso, ${ }^{23}$ a constante reinterpretação dos trabalhos de cunho historiográfico produzidos no medievo alerta sobre a necessidade de atentarmo-nos para tais textos como produtos complexos em que estavam envolvidos representações e simbolismos que extrapolam a simples relação com textos sagrados e clássicos, mas que se configuram como testemunhos coevos do momento de seu fazer, em que sua análise nos permite, até certo ponto, reconstituir uma cadeia não linear de saberes. É nesse sentido, portanto, que se inserem as ponderações de A escrita da história na Idade Média, um trabalho meritório não apenas por figurar como uma obra que reúne inquietações sobre esse importante tema escrita por pesquisadores brasileiros, mas que igualmente suscita a divulgação mais ampla sobre aquela parte fundamental da produção de conhecimentos realizada durante um período chave da história ocidental.

\footnotetext{
${ }^{20}$ SMALLEY, Beryl. Historians in the Middle Ages. Londres: Thames \& Hudson, 1974.

${ }^{21}$ TEIXEIRA, Igor Salomão. Ystoria sancti Thome de Aquino: hagiografia ou história? In: TEIXEIRA, Igor Salomão \& BASSI, Rafael (org.), obra desta resenha, p. 144.

${ }^{22}$ WHITE, Hayden. The content of form: narrative discourse and historical representation. Baltimore; Londres: John Hopkins University Press, 1987, p. 1-25.

${ }^{23}$ LE GOFF, Jacques. The medieval imagination. Traduzido por Arthur Goldhammer. Chicago: University of Chicago Press, 1988.
} 


\section{Referências bibliográficas}

ALMEIDA, Neri de Barros \& DELLA TORRE, Robson Murilo Grando. A História eclesiástica de Eusébio de Cesareia frente à tradição historiográfica clássica. In: TEIXEIRA, Igor Salomão \& BASSI, Rafael (org.). A escrita da história na Idade Média. São Leopoldo: Oikos, 2015.

BASSI, Rafael. Anna Commena, historiadora. Um estudo sobre a escrita da história no Império bizantino: o caso d'A Alexíada (séculos XI - XII). In: TEIXEIRA, Igor Salomão \& BASSI, Rafael (org.). A escrita da história na Idade Média. São Leopoldo: Oikos, 2015.

CAIE, Graham. The manuscript experience: what medieval vernacular manuscripts tell us about authors and texts. In: CAIE, Graham \& REVENEY, Denis (ed.). Medieval texts in context. Londres: Routledge, 2008.

FRANÇA, Susani Silveira Lemos. A rememoração do passado no rastro da prudência. In: TEIXEIRA, Igor Salomão \& BASSI, Rafael (org.). A escrita da história na Idade Média. São Leopoldo: Oikos, 2015.

GALBRAITH, Vivian Hunter. Historical research in medieval England. Londres: University of London, 1951.

GIVEN-WILSON, Christopher. Chronicles: the writing of history in late medieval England. Londres: Hambledon and London, 2004.

GRANSDEN, Antonia. Historical writing in England. Londres: Routledge, 1996.

GUENÉE, Bernard. História. In: LE GOFF, Jacques \& SCHMITT, Jean Claude (coord.). Dicionário temático do Ocidente medieval. Tradução de Hilário Franco Júnior. Bauru: Edusc; São Paulo: Imprensa Oficial do Estado, 2002.

GUIMARÃES, Marcella Lopes. As intenções da escrita da história no outono da Idade Média. In: TEIXEIRA, Igor Salomão $\mathcal{E}$ BASSI, Rafael (org.). A escrita da história na Idade Média. São Leopoldo: Oikos, 2015.

HAY, Dennis. Annalists and historians: western historiography from eighth to eighteenth centuries. Londres: Methuen; Nova York: Harper $\mathcal{E}$ Row, 1977.

LE GOFF, Jacques. The medieval imagination. Traduzido por Arthur Goldhammer. Chicago: University of Chicago Press, 1988.

MACEDO, José Rivair. Os estudos medievais no Brasil: uma tentativa de síntese. Reti Medievali Rivista, Firenze, vol. 7, n. 1, 2006, p. 1-9. Disponível em: http://www. dssg.unifi.it/_RM/rivista/saggi/RivairMacedo.htm. Acesso em: 03/03/2016.

MIATELLO, André Luis Pereira. Iacopo de Varagine a escrita da história no século XIII. In: TEIXEIRA, Igor Salomão \& BASSI, Rafael (org.). A escrita da história na Idade Média. São Leopoldo: Oikos, 2015.

RICHARDSON, Malcolm. Middle-class writing in late medieval London. Londres: Pickering $\mathcal{E}$ Chatto, 2011.

SOUTHERN, Richard. History and historians: selected papers by Richard Southern. Editado por Richard Bartlett. Malden, MA: Blackwell, 2004.

SIQUEIRA, André Luiz. Fantasmas celanenses: os usos do "Memoriale beati Francisci in desiderio aimae" na formação de uma consciência histórica franciscana no século XIII. In: TEIXEIRA, Igor Salomão \& BASSI, Rafael (org.). A escrita da história na Idade Média. São Leopoldo: Oikos, 2015. 
SMALLEY, Beryl. Historians in the Middle Ages. Londres: Thames \& Hudson, 1974.

TAYLOR, John. English historical literature in the fourteenth century. Oxford: Clarendon Press, 1987.

TEIXEIRA, Igor Salomão. Ystoria sancti Thome de Aquino: hagiografia ou história? In: TEIXEIRA, Igor Salomão \& BASSI, Rafael (org.). A escrita da história na Idade Média. São Leopoldo: Oikos, 2015.

VIAL, José Miguel de Toro. As crônicas universais e a cosmografia medieval. In: TEIXEIRA, Igor Salomão \& BASSI, Rafael (org.). A escrita da história na Idade Média. São Leopoldo: Oikos, 2015.

WHITE, Hayden. The content of form: narrative discourse and historical representation. Baltimore; Londres: John Hopkins University Press, 1987.

Recebido: 14/03/2016 - Aprovado: 28/04/2016 